\title{
Principles of petrochemical cluster' sustainability assessment based on its members' energy efficiency performance
}

\author{
A. N. Dyrdonova ${ }^{1, *}$, and T.S. Lin'kova ${ }^{1}$ \\ ${ }^{1}$ Nizhnekamsk Chemical Technology Institute (Branch) of Kazan National Research Technological University, Nizhnekamsk, Russia
}

\begin{abstract}
For the Russian economy, the most crucial prerequisite for its moving towards sustainable development would be strong improvement of performance of the domestic enterprises and production complexes. It is obvious that this issue should be addressed with due consideration of the special aspects relevant to social and economic growth of various Russian areas, along with creating a respective clusterbased infrastructure. Therefore, all arrangements aimed at performance efficiency improvement should be reconciled with the social and economic development strategies designed for a particular area, and should be well considered when working out strategic development plans for the regional industrial and territorial clusters, as well as particular enterprises and production plants. This paper includes an analysis of the dynamics pattern of the main indicators characterizing the energy use efficiency in regard to the largest enterprise forming the core of the petrochemical cluster in one of the Russian regions. The study furthermore shows the determined factors bringing the greatest impact on the production energy efficiency improvement. The authors also describe the prospects for production energy intensity reduction against the backdrop of the electric energy and power market liberalization, and explain how accommodation of the industrial clusters' activities to the changes taking place in the macroeconomic environment for business entities may determine the need for addressing a whole range of fundamentally new issues of methodological, methodical and organizational nature, which are relevant to development of a cluster behaviour strategy in response to the competitive electric energy market.
\end{abstract}

\section{Introduction}

Sustainability of industrial clusters, as well as performance of the enterprises operating in the petrochemical sector to a great extent determine formation of budgets of various levels, including, above all, the regional budgets that generally have a substantial influence on development of the social and cultural spheres in a region. Therefore, it is not a coincidence that performance efficiency of the petrochemical enterprises has always been under close attention of regional governing authorities. Improvement of industrial clusters' sustainability, as well strengthening the performance efficiency of the enterprises operating in the petrochemical sector depends on a wide range of external and internal factors. A high status among such factors is given to energy costs' impact on the final results of their activities.

High energy intensity of the production process is one of the most important constraints impeding the domestic petrochemical enterprises' competitive growth in the global market. Against the background of the ongoing global financial crisis, seeking solutions to this issue is of particular importance because it is primarily linked to the loss of interest in the products on the side of western partners, as well as abatement of product selling prices. All the aforesaid may be fully attributed to the performance of a largest domestic enterprise operating in the petrochemical sector - the Public Joint-Stock Company "Nizhnekamskneftekhim". It should be noted that Nizhnekamskneftekhim is the largest energy resources consumer among other enterprises running in the petrochemical sector of the Republic of Tatarstan. Nizhnekamskneftekhim is consuming $9.2 \%$ of electric energy and $29.2 \%$ of thermal energy generated by the entire energy system of the region. Therefore, the issues related to energy efficiency improvement are particularly relevant to this enterprise in the current conditions. The situation is aggravated by the continuous rise in the electricity and heat prices offered by the energy suppliers.

\section{Literature overview}

The issues pertaining to the rational use of energy resources, improvement of economic efficiency of energy-saving measures, as well as technologies being mastered at the enterprises making part of industrial clusters are covered in many studies. From the point of view of interest to the national economy of various countries, the energy efficiency issues are analyzed in the studies by G.-M. Shi, J. Bi, J.-N. Wang [1], J. Bing, L. Rui [2] and J.-L. Hu, S.-C. Wang, F.-Y. Yeh [3], S.

\footnotetext{
*Corresponding author: danauka@lenta.ru
} 
Honma and J.-L. Hu [4]. From the point of view of specificity of the investments, the issue of rational use of energy resources has been studied by R. Ayres, D. Lindenberger and B. Warr [5]. From the point of view of identification of cross-country patterns, the issue of energy efficiency of enterprises making part of integrated production systems has been set out and addressed in the studies by M. Filippini and L. Hunt [6]. The industrial sector-related cross-cultural comparisons that have been conducted as part of the investigations aimed at finding the ways to energy efficiency improvement can be found in the studies by E. Cagno, E. Worrell, A. Trianni and G. Pugliese [7]. The issues related to determination of energy conservation research directions, as well as energy efficiency improvement across particular enterprises are covered in the studies by E. Worrell, J.A. Laitner, M. Ruth, H. Finman [8].

Recently, various aspects of the development of industrial clusters, including the formation of competitive cluster formations $[9,10,11]$, the interaction of cluster elements and intercluster cooperation [12, 13], the methodology for evaluating the activity of cluster formations and calculating the effect of creating a cluster for the regional economy $[14,15]$ and others.

However, despite the numerous studies devoted to these issues, there is a lack of a holistic scientific concept of energy saving management, as well as an integrated methodology for improvement of energy efficiency and sustainability of the industrial clusters.

\section{Research methodology}

Analysis of the energy resources prices dynamics in the context of the production and commercial environment for Nizhnekamskneftekhim, as presented by the authors in Table 1, made it possible to find out that during 2012 2017 the electric energy prices increased by 2.4 times, thermal energy prices - by 2.7 times, fuel prices - by 2.2 times. All this, of course, could not but, firstly, affect the size of the company's expenditures, and, secondly, bring about a change in the relative share of energy costs in the enterprise's production cost structure.

Let's analyze the dynamics of the changes on the basis of the information related to the time period under review. Please refer to Table 2 .

Analysis of the data shown in the Tables above resulted in the following conclusions. First of all, it should be noted that throughout the period under review the production cost has been continuously increasing. Energy costs also have been steadily growing during the entire period under review, i.e. in 2012-2017. The share of energy costs in the entire production cost structure also increased in 2014 vs 2013 and in 2013 vs 2012, with reaching $17.64 \%$ in 2014 , and $18.06 \%$ in 2012 .

In 2014, mainly owing to revival of consumer demand for the company's products in the global market, as well as due to the measures related to the energy saving activities, the company managed to significantly improve the situation through decreasing by $1.1 \%$ the share of energy costs in the production cost structure along with an overall production cost increase by 12,244 mln Rubles in 2014. Regarding the data for 2017, one can notice a slight decrease in the relative share of energy costs in the total production cost. Energy return is reported to have multidirectional dynamics, with energy intensity being at a factor of 0.13 (on average).

Return on costs over 2012-2014 and 2015-2017 showed a noticeable downward trend, which is attributed to the fact that profit growth rates over the mentioned time periods were inferior to the production cost growth rates. General decline in the production cost (if we

Table 1. Price growth dynamics over 2012-2017 in regard to energy resources purchased by Nizhnekamskneftekhim, \%.

\begin{tabular}{|l|c|c|c|c|c|c|}
\hline \multicolumn{1}{|c|}{ Energy resource } & $\begin{array}{c}2013 \text { by } \\
2012\end{array}$ & $\begin{array}{c}2014 \text { by } \\
2013\end{array}$ & $\begin{array}{c}2015 \text { by } \\
2014\end{array}$ & $\begin{array}{c}2016 \text { by } \\
2015\end{array}$ & $\begin{array}{c}2017 \text { by } \\
2016\end{array}$ & $\begin{array}{c}\text { Increase in } 2017 \text { to } \\
2012, \%\end{array}$ \\
\hline Electrical power & 12.5 & 19.75 & 22.68 & 26.89 & 12.58 & 136.11 (by 2.4 times) \\
\hline Thermal power & 7.97 & 30.11 & 30.10 & 24.80 & 16.35 & 165.39 (by 2.7 times) \\
\hline Fuel & 6.79 & 15.93 & 29.93 & 11.64 & 19.94 & 115.38 (by 2.2 times) \\
\hline
\end{tabular}

Table 2. Dynamics of Nizhnekamskneftekhim's production expenditures over 2012-2017.

\begin{tabular}{|l|c|c|c|c|c|c|}
\hline \multicolumn{1}{|c|}{ Indicators } & 2012 & 2013 & 2014 & 2015 & 2016 & 2017 \\
\hline Production cost (total), mln Rubles & 105563 & 107371 & 119615 & 123313 & 131139 & 148497 \\
\hline $\begin{array}{l}\text { Costs per 1 Ruble of sold products } \\
\text { (revenues), kopecks }\end{array}$ & 84.28 & 89.61 & 90.01 & 81.88 & 85.48 & 91.58 \\
\hline Energy costs, mln Rubles & 15769 & 16422 & 17362 & 18489 & 19818 & 22188 \\
\hline $\begin{array}{l}\text { Share of energy costs in production costs, } \\
\%\end{array}$ & 17.56 & 18.06 & 16.98 & 17.64 & 17.80 & 17.57 \\
\hline Return on costs, \% & 18.65 & 11.60 & 11.10 & 22.13 & 16.98 & 9.19 \\
\hline $\begin{array}{l}\text { Energy efficiency (energy productivity), } \\
\text { thous. rbl / thous rbl. }\end{array}$ & 7.94 & 7.30 & 7.65 & 8.15 & 7.74 & 7.31 \\
\hline Energy intensity, thous. rbl/thous rbl. & 0.13 & 0.14 & 0.13 & 0.12 & 0.13 & 0.14 \\
\hline
\end{tabular}


Table 3. Energy costs structure for Nizhnekamskneftekhim over 2012-2017, \%.

\begin{tabular}{|l|c|c|c|c|c|c|}
\hline \multicolumn{1}{|c|}{ Energy resource } & 2012 & 2013 & 2014 & 2015 & 2016 & 2017 \\
\hline $\begin{array}{l}\text { Energy costs - total, } \\
\text { with breakdown by types of energy } \\
\text { resources: }\end{array}$ & 100.00 & 100.00 & 100.00 & 100.00 & 100.00 & 100.00 \\
\hline - electrical power & 24.0 & 24.1 & 25.8 & 25.4 & 28.5 & 31.0 \\
\hline - thermal power & 61.8 & 61.8 & 60.0 & 60.6 & 58.6 & 55.8 \\
\hline- fuel & 14.2 & 14.1 & 14.2 & 14.1 & 12.9 & 13.2 \\
\hline
\end{tabular}

compare 2014 with 2012) was equal to $6,405.71 \mathrm{mln}$ Rubles, which resulted in a decrease in return on costs down to $7.55 \%$, while in 2017 vs 2015 , the profit went down by $8,995.91 \mathrm{mln}$ Rubles resulting in a $5.88 \%$ decrease in return on costs. In 2015 (as compared to 2014), improvement of the situation owing to the reasons above described helped the company to increase its gross profit margin by 1,4006.89 mln Rubles, with an increase in return on costs by $11.03 \%$.

Another indicator of energy resources use efficiency is energy return (energy performance) that shows energy return per each Ruble spent on purchase of energy resources. This indicator's direction is opposite to the production energy intensity dynamics.

The Table above shows the company's energy costs structure with breakdown by types of energy resources. As can be seen from the data above shown, the highest share in the company's energy costs structure is taken by thermal energy (on average $\approx 60 \%$ ). The share of electric energy cost is $\approx 26.5 \%$, fuel cost is $\approx 13.5 \%$.

So, by 2015 , Nizhnekamskneftekhim managed to appreciably overcome the consequences of the crisis, which fact is proven by the company's profit growth, as well as the increase in the production profitability, and improvement of some other indicators. It should be noted that a significant contribution to company's performance efficiency improvement was optimization of the production energy efficiency, which in 2015 made it possible to reduce the share of the energy costs in the production cost structure, reduce the production energy intensity, increase the energy return (energy performance), whilst increasing profitability of investments in production. However, for 2016-2017 negative dynamics of the above mentioned indicators is observed.

Nevertheless, Nizhnekamskneftekhim has developed and successfully implemented three energy saving programs. The measures carried out under these programs allowed the company to reduce purchases of energy resources from external suppliers, and annually reduce the specific norms of energy consumption per unit of product output.

During validity of the a.m. Programs from 2000 to 2018, the company implemented almost 1,300 energysaving measures to a total amount of 2.1 bln Rubles. At the same time, 4.6 bln Rubles was saved owing to saving of:

$-5.8 \mathrm{mln}$ Gcal of thermal energy;

$-347 \mathrm{mln} \mathrm{kW} / \mathrm{h}$ of electric energy;

-192 thous. tons of fuel equivalent.
In order to reduce the energy costs and increase product competitiveness, Nizhnekamskneftekhim has commissioned the Unit GTU-75 which incorporates a new technology with higher technical and economic indicators. The Unit provides increased reliability and maneuverability of power equipment at Nizhnekamsk Cogeneration Station. Over a ten-year period, the Unit GTU-75 has produced $5.4 \mathrm{bln} \mathrm{kW} / \mathrm{h}$ of electric energy and $9.0 \mathrm{mln}$ Gcal of thermal energy.

Pursuant to the Federal Law No. 261-FZ "On Energy Saving”, the Center for Energy Saving Technologies at the Cabinet of Ministers of the Republic of Tatarstan conducted the 4th energy survey (energy audit) in 2016, which determined the status of energy use at the enterprise over the past five years and the remaining energy saving potential, as well as outlined energy saving measures and procedure for their implementation. The authority developed and issued "Energy Passport of Industrial Consumer of Fuel and Energy Resources" to Nizhnekamskneftekhim with validity until 2021.

In addition, as part of the program aimed at energy resources costs reduction, in accordance with the Rules for Retail Electricity Market Functioning, as well as in pursuance of Decree No. 530 issued by the Government of the Russian Federation, Nizhnekamskneftekhim entered the wholesale market of electric energy and power through the PEST sales company [16].

\section{Findings and discussion}

Driving a comprehensive energy-saving policy through all structural divisions in the industrial cluster becomes the most important strategic task, implementation of which is aimed at bettering the competitive advantages of the products both in the domestic markets and abroad. The company's undoubted achievement in terms of energy saving efforts reported over the period under review is that while the energy tariffs have continuously been increasing the company has managed to keep the production energy intensity indicators to be within 0.12 0.14 . However, despite the extensive work that has been done, in our opinion, the enterprise is not fully taking the opportunity for reducing its energy costs.

The matter is that completion of the electric energy and power market liberalization will produce a significant effect on growth of the entire domestic economy in the very near future, with entailing significant changes to the environment for both energy producers and energy consumers, including, first of all, the enterprises running in the petrochemical sector, 
which are distinguished, as has been mentioned above, for high energy intensity of their petrochemical production processes. Today, the energy market offers almost fully-formed new conditions and opportunities for improving the efficiency of energy resources not only through utilization of internal energy saving reserves but also through the use of new opportunities offered to the energy consumers by the liberalized electric energy and power market [14]. Therefore, liberalization of the electric energy and power market in Russia could be regarded as emergence of a new factor having a significant impact on competitive strength of the enterprises. And this applies primarily to the enterprises operating in the petrochemical sector.

At the same time, the greatest opportunities are opening up for the enterprises that have entered the wholesale market. Utilization of the relevant market mechanisms could help gaining tangible benefits. First, they give a possibility to purchase electric energy and power in a favorable market environment at a lower price, or selling it at a higher price. Second, energy cost saving becomes achievable within the framework of the projected values, regardless of any changes in the external factors, owing to the hedging tools available in the wholesale market. Third, it becomes possible to gain an extra profit through derivative financial instruments available in the energy market.

It should particularly be emphasized that the company's operations in the wholesale electric energy and power market in order to gain an extra profit is absolutely new practice for the domestic enterprises. It is a very specific type of market activities in terms of implementation. As such, in our opinion, it may even be singled out as a separate type of business, where two directions are clearly visible. First, purchasing of electric energy directly from the generating companies under bilateral agreements for the purpose of subsequent energy resale at a higher price in the day-ahead market. Second, purchasing and selling of derivative financial instruments on the energy stock exchange.

So, it will be for the first time that the domestic enterprises will obtain wide opportunities for creating their own energy strategies in case they get a new status of fully legitimate players in the electric energy and power market against the backdrop of the market liberalization. At the same time, they will no longer be limited to only seeking ways to reducing energy costs through energy-saving efforts. The enterprises' capabilities will be significantly expanded owing to the advantages of the energy product pricing mechanisms that are currently being formed in the market.

\section{Conclusions}

The lack of researches by domestic and foreign scientists, which would be intended to identify possible effects of electric energy and power market liberalization in terms of national economy operation, as well as develop methods for accommodation of the industrial cluster-based enterprises' energy cost management to the liberalized electric energy and power market, speaks to the need for further efforts in this direction.

In our opinion, accommodation of Nizhnekamskneftekhim's business activities to the changes occurring in the macroeconomic environment of the enterprises, predetermine the need for addressing a whole range of fundamentally new issues of methodological, methodical and organizational nature, which are relevant to development of a cluster behavior strategy in response to the competitive electric energy market. Once these issues are resolved, the enterprise will be able to expand its capabilities so as to seek resources for improving its production energy efficiency, as well and increasing its products competitiveness, along with making it possible to transpose the energy saving efforts into a different solution plane for addressing the challenges the enterprise is faced with.

\section{References}

[1] G.-M. Shi, J. Bi, J.-N. Wang, Chinese regional industrial energy efficiency evaluation based on a DEA model of fixing non-energy inputs Energy Policy 38(10), 6172-6179 (2010)

[2] J. Bing, L. Rui, Economic analysis of energy efficiency in China's economy Actual Problems of Economics 124(10), 367-372 (2011)

[3] J.-L. Hu, S.-C.Wang, F.-Y. Yeh, Total-factor water efficiency of regions in China Resources Policy 31(4), 217-230 (2006)

[4] S. Honma, J.-L. Hu, Efficient waste and pollution abatements for regions in Japan International Journal of Sustainable Development and World Ecology 16(4), 270-285 (2009)

[5] R. Ayres, D. Lindenberger, B. Warr, The underestimated contribution of energy to economic growth Structural Change and Economic Dynamics 27, 79-88 (2013)

[6] M. Filippini, L. Hunt, Energy demand and energy efficiency in the OECD countries: A stochastic demand frontier approach Energy Journal 32(2), 59-80 (2011)

[7] E. Cagno, E. Worrell, A. Trianni, G. Pugliese, A novel approach for barriers to industrial energy efficiency Renewable and Sustainable Energy Reviews 19, 290-308 (2013)

[8] E. Worrell, J. Laitner, M. Ruth, H. Finman, Productivity benefits of industrial energy efficiency measures Energy 28(11), 1081-1098 (2003)

[9] Porter M., Competition (Moscow: Publishing House «Williams») 258 (2005)

[10] P. Maskell, M. Larenzen, The Cluster as Market Organization DRUID Working Paper 14, 29 (2003)

[11] A. N. Dyrdonova, A.I. Shinkevich, N.Y. Fomin, and E.S. Andreeva, Formation and development of industrial clusters in the regional economy Revista Espacios 40(1), 21-28 (2019)

[12] V.P. Feldman, Innovation in cities: Science, based on diversity, specialization and localization competition European Economic Review 43, 409-429 (1999) 
[13] S.A. Rosenfeld, Bringing Business Clusters into the Mainstream of Economic Development European Planning Studies 5, 3-23 (1997)

[14] A.N. Dyrdonova, Improvement of performance efficiency of the enterprises making part of integral production systems in the region Revista Espacios 40(14), 24-31(2019)

[15] T.S. Lin'kova, D.N. Zemskii, S.K. Kurlyand, N.I. Zemskii, The stabilisation of SKI-3 polyisoprene rubber by polyoxypropylated aromatic amines International Polymer Science and Technology 43(5), 18-21 (2016)

[16] A.N. Melnik, A.N. Dyrdonova, Energy efficiency improvement ways in industrial clusters of the region Mediterranean Journal of Social Sciences 6(3), 141-145 (2015) 